\title{
The design and implementation of moodle group discussion plugin
}

\author{
Yuman Lin \\ Department of Instruction Technology \\ Shaoguan University \\ Shaoguan, China \\ e-mail: gd_lym@163.com
}

\begin{abstract}
Moodle is an excellent course management system. Group discussion plugin can let teachers and students make full use of the Moodle platform to teach and learn, substantially improve the convenience for students and teachers to discuss questions, fulfill the auxiliary function of the network to the teaching. Moodle group discussion plugin mainly implement two parts of function: teachers part, teachers can create and delete group, delete group members, implement the function of posting, uploading and downloading files; students part, students can join and exit the group, implement the function of discussion through posting, uploading and downloading files. The design and implementation of these two parts of function, and some related keys of technique were described detailedly in this essay.
\end{abstract}

Keywords- moodle; plugin; group discussion

\section{INTRODUCTION}

Moodle is initially developed by an Australian teacher -Ph.D Martin Dougiainas. Because of its free open source and updated educational concept, a growing number of professionals as well as devotees with great enthusiasm for education take their part in the design and development of the system which makes its powers become more and more strong.Moodle became one of the most popular CMS systems aroud the world.Basing on Constructivist Educational Theory, Moodle is designed and developed as an open source software that can help teachers build and manage the online class in high quality.

Its combination between online teaching module and dynamic combination module sets free, thus seems teachers build the online course just like piling up building blocks. Under Moodle, many kinds of teaching modules are supported to assist teachers and students to communicate in an active collaboration way on-line, communicational details could be presented through on--line activities and assessment records, and teachers are offered embedded webpage editor that is regarded as seen means gotten to make the contents of the course easy.

Major functions of Moodle can be divided into three parts: they are website management, study management and course management, some of which contain flexible and rich activities of the course like blog, forum, test, learning resource, questionnaire, homework, online chat room, voting, wiki and so on.

As a powerful interactive tool of Moodle, the Discussion one is one of the network activity modules that deserves attention. Within Moodle, communications between teachers and students or from students to students are out of the control of limitation to space and time. Instead, no matter when or where, reaching the internet, users can discuss a certain educational issue, share ideas and information, all of which could be viewed in the discussion part.

While using Moodle, a phenomenon of discussion on Moodle has been found that it could only open to students who are members of all courses. Students don't have their own choice to choose one group to participate in. It can be said that the study in groups on Moodle is kind of easy.

In order to make the discussion between teachers and students become more convenient, the essay is aim at exploring how to strength the group discussion on the base of previous functions of Moodle. group discussion plugin enables teachers to set up groups as well as arrange group members, or students to have their own choice to choose one group to begin discussion.By using group discussion plugin, the purpose of group studying is achieved because each group is indeed individual whose discussed issues and shared information are given over to certain members and course teachers.

The main contents of this essay include the following: The needs of group discussion plugin Definition for proper powers between teachers and students

Achievement for the combination of Moodle

\section{PROGRAM FOR SECOND DEVELOPMENT OF GROUP DISCUSSION PLUGIN}

\section{A. Analyzing the needs of group discussion plugin}

1) Analyzing the needs of the faculty.

First of all, teachers must be empowered to set up groups and manage all students of courses which means they can add members to a group, deleting students' names in the list of group not course and allowing students to join the groups. Secondly, teachers could send remarks, upload and download data and watch on students' remarks. Finally, teachers could dismiss groups after the courses have been finished.

- $\quad$ Setting up activity module.The module is used for setting and installing basic information about the group discussion including the name and account of one group.

- Managing posts module.The module manage the discussion contents that is the remarks posted by students. 
Teachers not only could delete their owns, but also could do the students' as well as upload and download resources.

- $\quad$ Managing members of group module.The module:is for managing members of groups which enables teachers to add and delete members of group and at the same time, to allow or refuse application from other students who is nọt belong to some group.

2) Analyzing the needs of the students.

Students are free to choose which group they want to join, but they can not join two groups at the same time. They havye rights to post and delete their opinion when they join the group and become members. Also, they can upload their own study resource among the members of the same group or download materials from other members of the group. Of course, they have their choice to withdraw the group.

\section{B. Designation of group discussion plugin interface}

The group discussion plugin was designed as kind of activity module, so the interface of it includes the interface of database and the interface of privileges.

- Designation of the database interface.The database interface of moodle is the funtion 'upgrade_activity _modules()'which is defined in the file '../lib/ adminlib.php'.The file $\mathrm{xml}$ is designed with the 'xmldb.dtd' offered by Moodle, thus name it 'install.xml' under the rule of Moodle. Then create a folder called ' $\mathrm{db}$ ' in folder 'xztl' which belongs to folder mod. After that, move the file install.xml into folder $\mathrm{db}$, a network manager webpage comes to view, and the following step is to click the Notification.In this way,data object defined by the file install.XML would be installed into database automatically.

- Designation of the privilege interface.There are two functions, 'get_context_instance( )' and 'has_capability ( )' , which were used to judge if the user has permissions to read and write. Function 'get_context_instance()' was used to obtain context, function 'has_capability()' was used to judge if the user has this ability in the context.

\section{SYSTEM TESTING}

\section{A. Functional testing of teachers}

The functions of faculty includes three modules,there are setting up activity module, managing posts module and managing members of group module.

- Setting up activity module.Faculty has the ability to create group, install basic information about the group discussion including the name and account of one group. The following Figure 1 shows the interface of create group.

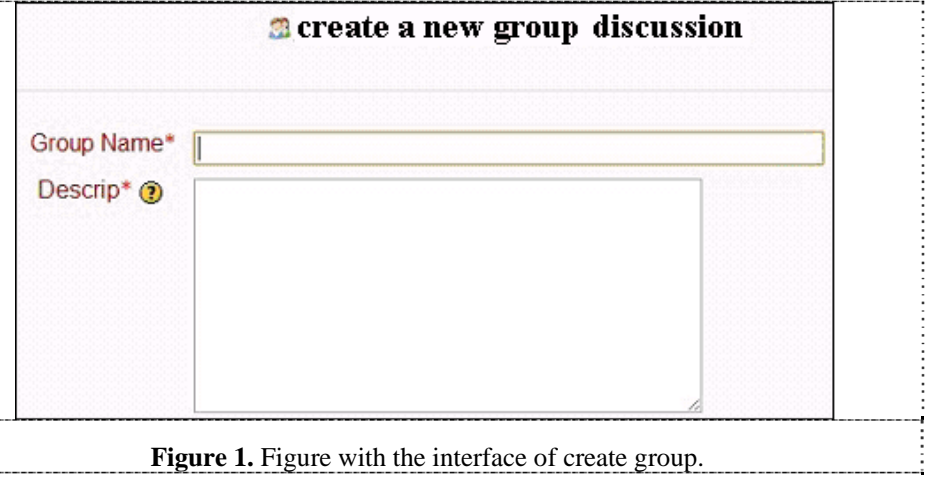

- Managing posts module.By using the managing posts module, teachers not only could delete the remarks posted by themselves, but also could do the students' as well as upload and download resources. The following table 1 shows the code of delete posts.

Table 1. The code of delete posts.

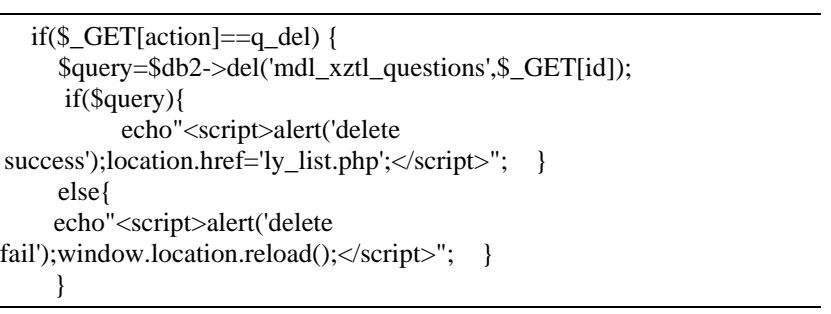

- Managing members of group module.The module enables teachers to add and delete members of group and at the same time, to allow or refuse application from other students who is not belong to some group. The following Figure 2 shows the interface of managing members of group.

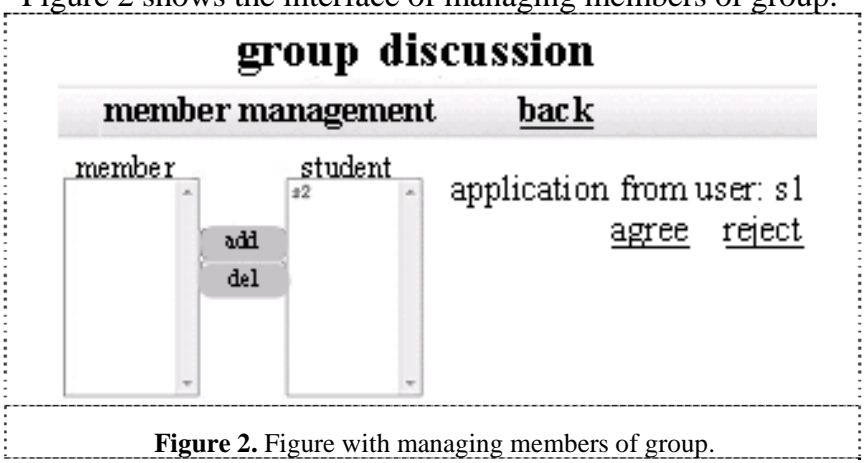

\section{B. Functional testing of students}

When they choose which group they want to join,only their applications are accepted that do students can become members of the group.And then they will have rights that members of group have. The following table 2 shows the code of join group.

Table 2. The code of join group. 


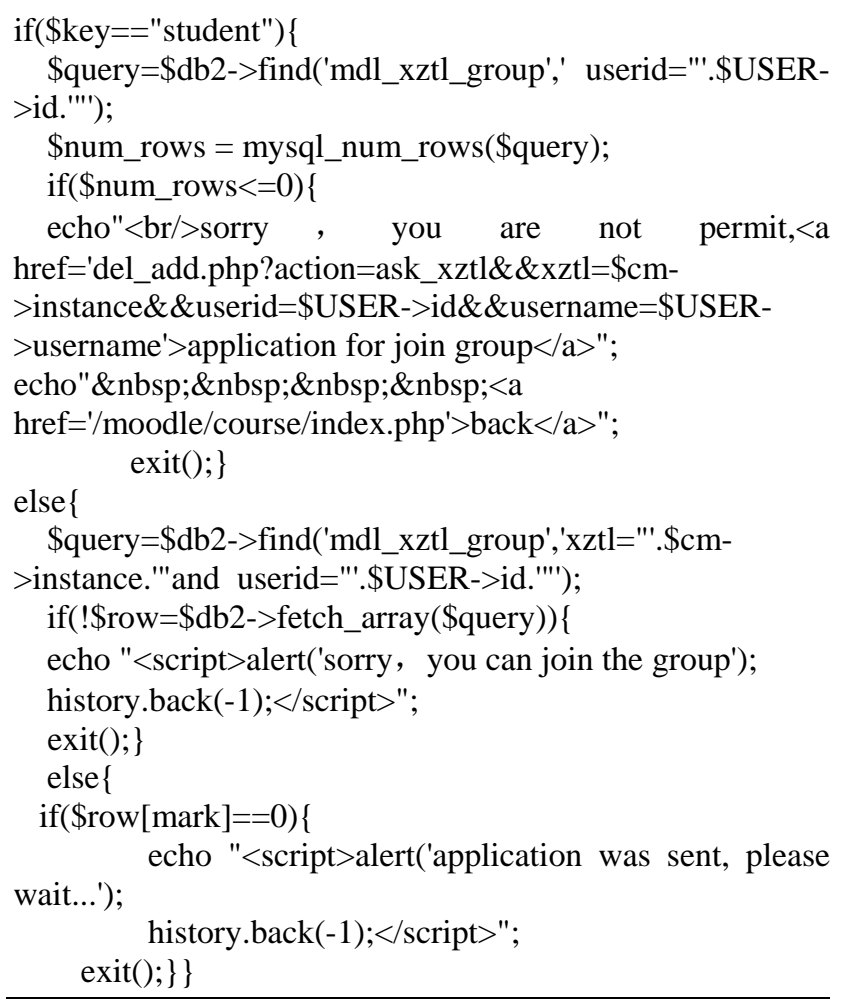

\section{CONCLUSION}

Concerning group discussion could not be achieved with the platform of Moodle, the essay extends the design of plugin in group discussion and makes it come to use based on Moodle. In the process of designation and realization, plugin in group discussion has reached the two goals, the database interface and privilege interface were called successful;Groups can be set up and through which discussion could be made successfully.

\section{REFERENCES}

[1] Developer_documentation[EB/OL].[2010-10-09]. http://docs.moodle. org/en/ Developer_documentation.

[2] Moodle [EB/OL].[2010-10-08]. http://moodle.org/.

[3] Xu Li,Wang Yao,Wang Weicong,Wang Guanzhong,"Moodle System Clustering Solutions and Case Analysis," Computer Applications and Software, Vol.29,No.1, 2012, pp.224-229

[4] Wang Chunhong, "Design Research Network Teaching Interactive Learning Activities in Moodle," Microcomputer Applications, Vol.28,No.2, 2012, pp.28-30

[5] Ma Yan, "Web 2.0 Autonomous Learning Platform Construction Based on Moodle, ” Microcomputer Information, No.11, 2011, pp.5961

[6] YE Hong, TIAN Xingyan, "Secondary Development Of Moodle, ” Microcomputer Information, No.9, 2011, pp.123-124

[7] Zhang Yanyan, "Design and Implementation of SIC Virtual Environment Based on Moodle--Taking the Library of Nanhai Campus of South China Normal University as an Example, ” Journal of Modern Information, Vol.31, No.8, 2011, pp.62-65 